\begin{tabular}{|c|c|}
\hline$S$ sciendo & 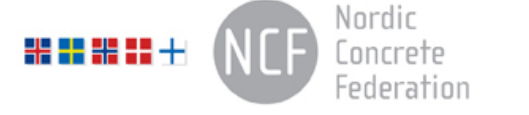 \\
\hline $\begin{array}{l}\text { (C) Article authors. This is an open access article distributed under } \\
\text { the Creative Commons Attribution-NonCommercial-NoDerivs } \\
\text { licens. (http://creaticecommons.org/licenses/by.nc-nd/3.0/). }\end{array}$ & $\begin{array}{l}\text { ISSN online } 2545-2819 \\
\text { ISSN print } \quad 0800-6377\end{array}$ \\
\hline DOI: $10.2478 /$ ncr-2021-0005 & $\begin{array}{l}\text { Received: March 26, } 2021 \\
\text { Revision received: Nov. 29, } 2021 \\
\text { Accepted: Nov. 29, } 2021\end{array}$ \\
\hline
\end{tabular}

\title{
Application of an Improved Empirical Model for Rheology Prediction of Cement Pastes Modified with Filler from Manufactured Sand
}

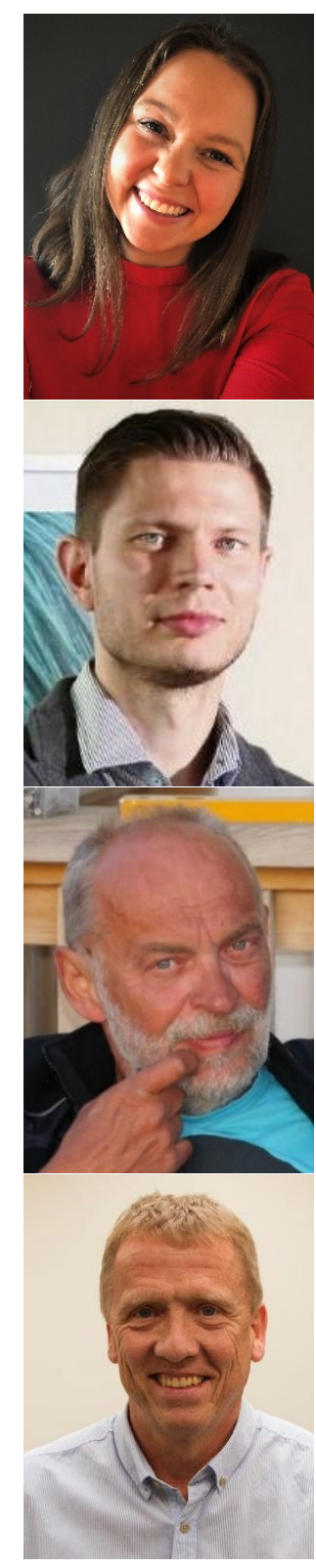

Elisabeth Leite Skare

M. Sc., Ph.D. candidate

Norwegian University of Science and Technology

Department of Structural Engineering

Richard Birkelands vei 1a, 7491 Trondheim, Norway

e-mail: elisabeth.1.skare@ntnu.no

Rolands Cepuritis

M. Sc., Ph.D., Adj. Associate Professor (NTNU)

Senior Project Manager

Norcem AS

Lilleakerveien 2A, 0216 Oslo, Norway

e-mail: rolands.cepuritis@ntnu.no

Ernst Mørtsell

Ph.D., Adj. Professor (NTNU)

R\&D Manager

Norbetong AS

Lilleakerveien 2B, 0216 Oslo, Norway

e-mail: ernst.mortsell@ntnu.no

Sverre Smeplass

Chief Adviser

Skanska Norge

Lakkegata 53, 0187 Oslo, Norway

e-mail: Sverre.smeplass@skanska.no 


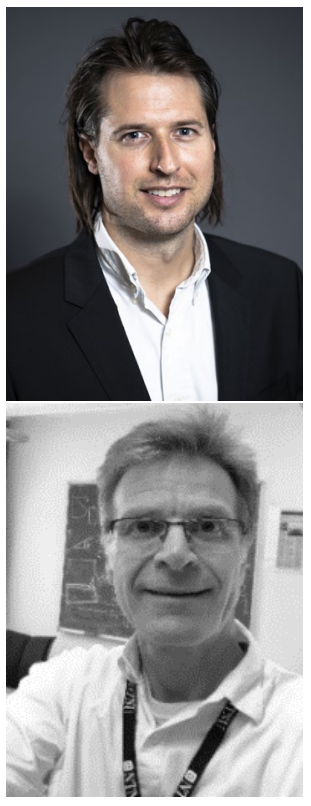

Jon Spangenberg

Ph.D., Associate Professor

Technical University of Denmark

Department of Mechanical Engineering

Building 425, room 224

2800 Kgs. Lyngby, Denmark

e-mail: josp@mek.dtu.dk

Stefan Jacobsen

Ph.D., Professor

Norwegian University of Science and Technology,

Department of Structural Engineering

Richard Birkelands vei 1a, 7491 Trondheim, Norway

e-mail: stefan.jacobsen@ntnu.no

\begin{abstract}
There is a need for simple but precise prediction models for proportioning concrete with manufactured sand, for use in ready-mix concrete production. For the last two decades, the particle-matrix model has been used in Norway for proportioning and prediction of concrete flow based on the properties and proportions of two concrete phases: coarse particles and filler modified cement paste (matrix). This paper presents experimental testing of 117 cement pastes of which 107 contain filler, i.e. particles < 125 microns, from manufactured sand. Based on compositions and properties of ingoing materials in these mixes, an empirical equation is developed that predicts the rheological properties plastic viscosity, yield stress, flow resistance ratio and mini slump flow. Optimization by regression analysis provides a practical microproportioning equation that readily can be used as input in concrete proportioning with the particle-matrix model. The equation provides a coefficient of determination $R^{2}=0.98$ for plastic viscosity, $R^{2}=0.95$ for mini slump flow, $R^{2}=0.91$ for flow resistance ratio and $R^{2}=0.80$ for yield stress.
\end{abstract}

Key words: Rheology, empirical model, cement paste, filler, manufactured sand.

\title{
1. INTRODUCTION
}

Controlling rheological properties is of major importance for the ready-mix concrete industry, and reliable prediction models are essential for efficient optimization of mix designs. However, validation of rheological prediction models for a given set of materials requires experimental testing. It is both economical and efficient to perform testing on small cement paste samples, and such small-scale testing has shown to be promising for rheology prediction of equivalent concrete mixes [1]. The literature provides numerous approaches to predict suspension rheology. Several models are based on packing, among others the viscosity models presented in [2-7]. Spangenberg et al. [8] verified that the viscosity models in [2-3] provide high prediction accuracy, by investigating their applicability on bimodal suspensions with hard spherical particles. Though most traditional viscosity models are simplified packing models ignoring particles interactions, Damineli et al. [9] show that the Particle Interference Model predicts viscosity of filler modified 
cement paste (matrix) by correlating physical aspects of particles and fluids. Predictive yield stress models in recent literature have been improved to include aspects like particle size distributions (PSDs), volume fraction of solids and inter-particle forces, such as the work presented in [10-14]. Another approach for modelling suspension rheology is the lubricating liquid thickness around all particles, proposed by Powers [15]. The liquid thickness is inversely proportional to the volumetric specific surface area (VSSA). Matrix rheology is found to be strongly affected by the VSSA of the ingoing powder materials, defined as surface area per volume of a material [16-17].

For the prediction methods to be useful for ready mix concrete plants, the required input data must be accessible without too advanced and expensive test methods [18]. Simplicity of the models is valued, as availability is considered crucial for the implementation of the test methods at the ready mix concrete plants [18]. Even though numerous rheology models exist, the literature on their applicability on matrices with filler from manufactured sand is sparse. As global resources of natural sand are running short, use of manufactured sand in concrete is increasing [19]. Cepuritis et al. [16] state that a pronounced difference between natural and manufactured sand is the higher fines content of the latter, which significantly increases the VSSA. The amount of fines depends on the production process, but is especially high for manufactured sand produced by Vertical Shaft Impactor (VSI) crushing. Bengtsson and Evertsson [20] found that the amount of fines increased with increased rotor velocity of the VSI crushing, resulting in a fines content (particle diameter $<0.125 \mathrm{~mm}$ ) of approximately $15 \%$ for high rotor velocity. However, in order to produce sand with density similar to that of natural sand, a high rotor velocity is necessary. The increased VSSA has a major impact on paste rheology, and its effect was quantified on filler modified cement pastes in [16-17]. Linear relations between VSSA and the rheology were found in [16], and the rheological effect of different mineralogy was highlighted by experiments with controlled VSSA. Similar linear relations were found in [17] and quantified for the total volume weighted VSSA of all ingoing powders except for silica fume, where it was impossible to relate its effect on rheology linearly to surface area, presumably due to the kind of non-linear behaviour observed by Wallevik [21]. In [18], an empirical equation was developed and applied on matrices with crushed aggregate fillers, with emphasis on simplicity and applicability of the equation for the ready-mix concrete industry. The mix program consisted of two types of crushed filler, one natural filler, four different types of cement, silica fume, one superplasticiser (SP) and one plasticiser (P). The SP- and P-dosages were kept constant for all mixes, and an individual equation was developed for each filler type. The empirical equation was a fitting model based on the particle matrix method, where matrix rheology was predicted based on mix composition [18]. In a sense it may be said to be similar to neural network-based models like [22], where the behaviour of the material is learned by a new form of experience based on numerical simulation.

This paper presents an experimental study of 117 matrices, consisting of four different crushed fillers, two different cement types, biotite, fly ash, silica fume, and one type of SP with dosages between $0.6-1.75 \%$ of cement weight. The scope of the paper is to further develop the empirical equation in [18] to account for large parameter variations. The overall goal is to establish a proportioning tool for the ready mix concrete industry, that is applicable also for matrices with manufactured sand. First, the original empirical equation is introduced, followed by a brief presentation of the material data and experimental test program. In the results section, a new empirical equation is presented, and the applicability of the equation is investigated on the 117 matrices. 


\section{2.}

THE EMPIRICAL EQUATION

The term microproportioning is proposed for the process of quantifying and predicting the rheology of filler-modified paste based on composition and part materials data for all fluids and particles with a diameter less than $125 \mu \mathrm{m}$. So far, the term was limited to quantify the relationship between the VSSA of the filler and the rheology of the paste [17, 19]. Based on the microproportioning principle, an empirical equation was developed by Mørtsell in 1996 [18] in the form of a power law describing the flow resistance ratio, $\lambda_{q}$. The flow resistance ratio is a unitless parameter that describes the rheological properties of cementitious suspensions, described in detail in [19]. The empirical equation is given on the form:

$$
\lambda_{q}=k \times\left(k_{c} \times \frac{c}{w}+k_{s} \times \frac{s}{c}+k_{f} \times \frac{f}{c}\right)^{n}
$$

Where $k_{c}, k_{s}$ and $k_{f}$ are material factors for cement, silica fume and filler, respectively, and $k$ and $n$ are constants obtained from optimization by curve fitting. For the materials used in [18], the factors equalled: $k_{c}=0.200, k_{s}=0.555$ and $k_{f}=0.154-0.311$. Eq. (1) was optimised, via $k$ and $n$, for three set of matrices with different crushed fillers, resulting in $R^{2}$-values between 0.98 and 0.99 for the three datasets. The matrices consisted of cement, crushed fillers, silica fume and plasticizer/superplasticiser. The plasticizer- and superplasticizer dosages were kept at a constant percentage of the cement weight for all matrices.

\section{EXPERIMENTS}

\subsection{Materials data and mix compositions}

Some of the matrices presented in this paper are the same as presented in [17], but in addition 11 new matrices are included here. The matrices consist of either Standard FA cement (CEM II/BM 42.5 R) or Industry cement (CEM I 52.5 R) from Norcem AS, as well as the superplasticizer Dynamon SR-N from Mapei. Some matrices also contain Norcem Fly ash (FA) and/or Elkem Microsilica 940-U. Four crushed aggregate fillers sieved mechanically at $0.125 \mathrm{~mm}$ are used (Table 1). The fillers denoted Fine, Intermediate and Coarse originate from the same rock type, and is mainly composed of feldspar and quartz. They differ from each other by being extracted at cut size $63 \mu \mathrm{m}, 125 \mu \mathrm{m}$ and $500 \mu \mathrm{m}$, respectively, in the air-classification process. The fourth filler is denoted VSI, being a Vertical Shaft Impactor (VSI) crushed 0/2 mm filler. The densities were measured by helium pycnometry. In addition, industrial biotite (mica) GW-MB-A230 with density $2.84 \mathrm{~g} / \mathrm{cm}^{3}$ from Great Wall Mineral [23] was used in some mixes. 
Table 1 - Densities, diameters, extraction cut size and producers of the four crushed aggregate fillers.

\begin{tabular}{lllll}
\hline $\begin{array}{l}\text { Material } \\
\text { designation }\end{array}$ & $\begin{array}{l}\text { Density } \\
{\left[\mathbf{g} / \mathbf{c m}^{3}\right]}\end{array}$ & $\begin{array}{l}\text { Particle } \\
\text { diameter }[\boldsymbol{\mu m}]\end{array}$ & $\begin{array}{l}\text { Production } \\
\text { cut-size } \\
{[\mu \mathrm{m}]}\end{array}$ & Producer \\
\hline Fine & 2.65 & $0-125$ & $63 \mu \mathrm{m}$ & Velde Pukk AS \\
Intermediate & 2.65 & $0-125$ & $125 \mu \mathrm{m}$ & Velde Pukk AS \\
Coarse & 2.65 & $0-125$ & $500 \mu \mathrm{m}$ & Velde Pukk AS \\
VSI & 2.75 & $0-125$ & $2000 \mu \mathrm{m}$ & Feiring Bruk \\
\hline
\end{tabular}

Originally, 125 matrices were proportioned, but 8 of the mixes were too viscous to perform the FlowCyl test on, hence 117 matrices are presented in this paper. Appendix A supplies detailed information about the mix compositions for all matrices. The matrices were designed to cover a wide range of rheological parameters, hence mixes outside the practical range used in ready mix concrete production appear.

\subsection{Volumetric specific surface area}

The volumetric specific surface area (VSSA) is defined as surface area per volume of a powder material [19] and is calculated from the PSD obtained from the X-ray machine Sedigraph III Plus in this study. The test procedure used in the current study is described in [17]. As explained in [17], the VSSA of each material was calculated by multiplying the particle surface areas of each bin by their volume percentages within that bin. The VSSAs for all dry materials except silica fume are provided (Table 2), since Sedigraph III Plus measures particles down to $1 \mu \mathrm{m}$, whereas the mean diameter of silica fume is approximately $0.1 \mu \mathrm{m}[24]$.

Table 2 -VSSA for all dry materials, except silica fume, calculated from the PSDs obtained from the Sedigraph-analysis.

\begin{tabular}{ll}
\hline Material & $\begin{array}{l}\text { Volumetric specific surface area } \\
{\left[\mathbf{m m}^{\mathbf{2}} \mathbf{\mathbf { m } ^ { 3 }} \mathbf{3}\right]}\end{array}$ \\
\hline Fine filler & 728 \\
Intermediate filler & 367 \\
Coarse filler & 522 \\
VSI filler & 260 \\
Biotite & 1122 \\
Standard FA & 829 \\
cement & 1302 \\
Industry cement & 970 \\
Fly Ash & \\
\hline
\end{tabular}


In this study we define $V S S A_{\text {matrix }}$ as the sum of volume weighted contributions from all ingoing matrix powders except silica fume, calculated from Eq. (2).

$$
V S S A_{\text {matrix }}=\sum_{i} V S S A_{i} \times \Phi_{i}
$$

Where $\Phi_{i}$ is the volume fraction of powder material $i$ in the matrix.

\section{3}

Mixing and rheology measurements

All matrices were mixed by the procedure in [25] in volumes of 2.0 litres. First, all dry materials were mixed in a Hobart mixer, model N-50, with a standard flat blade for two minutes. Subsequently, water and superplasticizer were mixed together for one minute. Subsequently, the wet-mixing of all materials was performed by a handheld drill (Tectool model TCD 180-30) with an attached steel paddle, specially designed for mixing cement suspensions. All materials were mixed at high speed for two minutes, and then left at rest for another two minutes. Lastly, the materials were mixed at low speed for two minutes. Directly after mixing, the flow resistance ratio, Bingham yield stress $\left(\tau_{0}\right)$ and plastic viscosity $(\mu)$ were measured for each of the matrices. The mini slump test was performed directly after the FlowCyl measurement, and the same paste that had been tested in the FlowCyl was reused in the mini slump cone. The $\lambda_{q}$ measurements were performed with the simple test equipment FlowCyl, and the Bingham parameters $\tau_{0}$ and $\mu$ were obtained from Anton Paar rheometer analysis.

The FlowCyl test apparatus was developed by Mørtsell [18] and is a modification of the Marsh cone. The FlowCyl is a cylinder ending in a $\mathrm{V}$-funnel with a narrow nozzle outlet. The inner diameter of the cylinder is $80 \mathrm{~mm}$ and the outlet inner diameter is $8 \mathrm{~mm}$ (Figure 1). The test principle is analogous to the Marsh cone test principle, where the container is placed vertically in a rack above an electronic scale connected to a computer. While the outlet is closed, the FlowCyl is filled with cement paste up to the level of $15 \mathrm{~mm}$ below the top edge. Then, the outlet is opened, and the weight increase is recorded every other second. The dimensionless parameter $\lambda_{q}$, is defined as the difference in flow rate between the test material and an "ideal" fluid with no internal resistance and no external cohesion or friction.

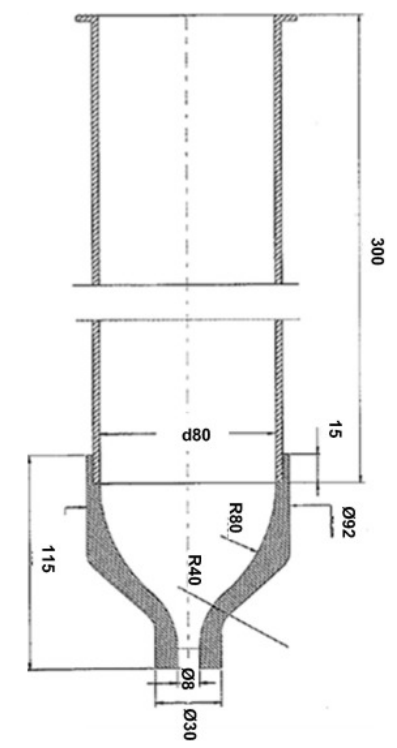

Figure 1 - The geometry of the FlowCyl test apparatus. Illustration adopted from [18]. 
The Bingham parameters, $\tau_{0}$ and $\mu$, were measured on $10.5 \mathrm{ml}$ samples at $20^{\circ} \mathrm{C}$ by an Anton Paar Physica MCR 300 rheometer equipped with a flat bottom bob-in-a-cup geometry. Such equipment has successfully been used in previous studies to quantify the rheological response of cementitious materials [26-28]. The bob had an outer diameter of $24.580 \mathrm{~mm}$ and a length of $50.000 \mathrm{~mm}$. The inner diameter of the cup was $28.901 \mathrm{~mm}$. The gap at the bottom of the bob was set equal to the gap at the side surface. First, the paste was homogenized for 30 seconds at a shear rate of $60 \mathrm{~s}^{-1}$, followed by rest for another 30 seconds. Thereafter, the paste was subjected to linearly increasing shear rates from $1 \mathrm{~s}^{-1}$ to $60 \mathrm{~s}^{-1}$ over a period of 3 minutes ( 30 steps of 6 seconds), followed by a step down of shearing from $60 \mathrm{~s}^{-1}$ to $1 \mathrm{~s}^{-1}$ for further 3 minutes. The slope of the down-curve (decreasing shear rate) was used to calculate $\mu$, while the intercept at zero shear rate was used to calculate $\tau_{0}$.

The truncated mini-cone that was used in this study had a top diameter of $39 \mathrm{~mm}$, a bottom diameter of $89 \mathrm{~mm}$ and a height of $70 \mathrm{~mm}$. A smooth plexi glass plate was used as the base for the measurements. The mini-cone was filled with matrix to the level of the top of the cone. Then, the cone was gently lifted and the diameter of the matrix at stoppage was measured in two orthogonal directions. The mini-slump flow value was then calculated as the mean of the two measured diameters.

\section{4.}

\section{RESULTS AND DISCUSSION}

The design of the new empirical equation is developed based on the correlation between single mix design parameters and the measured rheological values. As the mix designs are spanning over a large variation in materials and dosages, several material parameters are varying at the same time, making it difficult to point out a clear rheological trend for each of the individual parameters. However, the five material parameters showing the clearest trend to the measured flow resistance ratio is plotted (Figure 2). In the figure, the mix parameters are normalized based on maximum span of the different parameters. The solid fraction, $\phi$, ranges from 0.39 to 0.55 in the experiments, hence, $\phi=0.39$ corresponds to 0.0 and $\phi=0.55$ corresponds to 1.0 . Furthermore, $w / p$ ranges from 0.29 to $0.57, w / c$ from 0.40 to 1.04 and $w / b$ from 0.40 to 0.81 , where $w, p, c$ and $b$ denote water, powder, cement and binder, respectively. Lastly, VSSA matrix ranges from 285 $\mathrm{mm}^{2} / \mathrm{mm}^{3}$ to $551 \mathrm{~mm}^{2} / \mathrm{mm}^{3}$. Note that Figure 2 is an illustration showing the typical trend that was observed for the considered mixes and is a simplification from the true observations. The figure shows the regression lines for the considered parameters. The slopes of the trendlines indicate that the powder- and binder concentration has the strongest relative influence on the flow

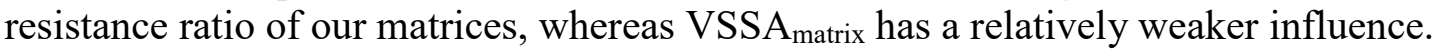




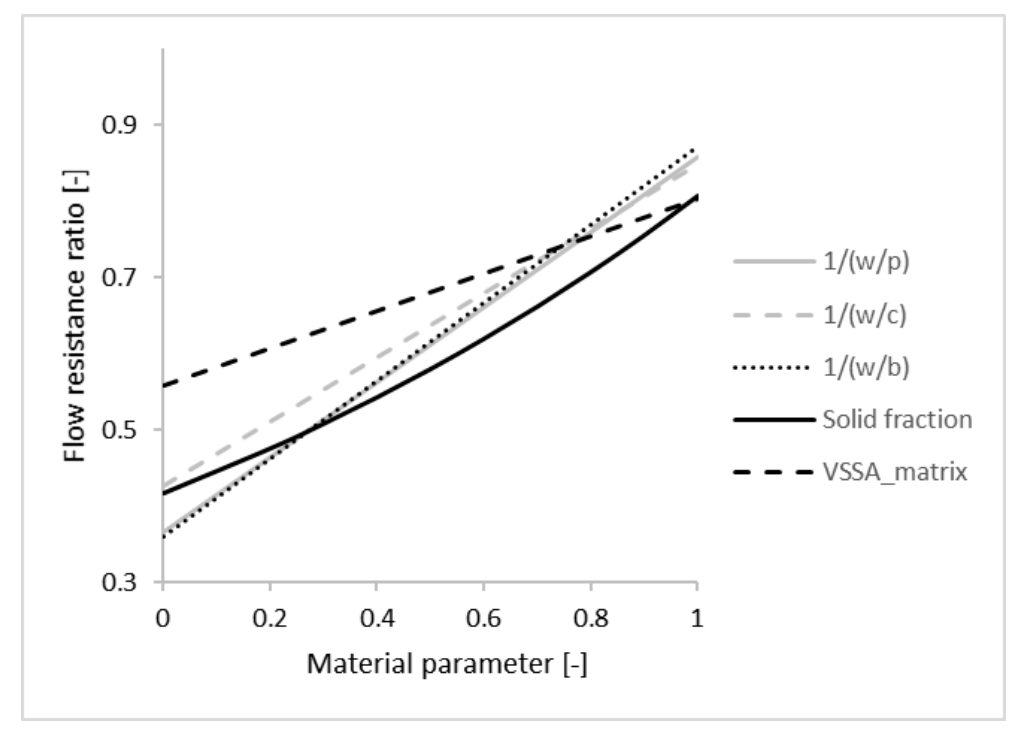

Figure 2 - Illustration of the observed trend between the flow resistance ratio and five different normalized material parameters.

The observed trends between the material parameters and the measured rheology parameters provided useful information with respect to which material parameters the new empirical equation should contain, as well as how each parameter affects the matrix rheology. The new empirical equation is shown in Eq. (3). $\Gamma$ represents an arbitrary rheology parameter, and the different $k_{x}$ factors are obtained by regression analysis using the built in Solver-function in Excel.

$$
\Gamma=\left(k_{1} \frac{V S S A_{\text {matrix }}}{100}-k_{2} \phi-k_{3} \frac{w}{p}-k_{4, i} \frac{S P}{c}+k_{5, i} \frac{c}{w}+k_{6} \frac{b i o}{f}+k_{7} \frac{F A}{b}+k_{8} \frac{s}{b}+k_{9, j} \frac{f}{b}\right)^{n}
$$

where $w, p, S P, c, f, b, F A, s$ and bio represent mass of water, powder, superplasticizer, cement, filler, binder, fly ash, silica fume and biotite, respectively, and $\phi$ is the solid fraction of the matrix. The different cement types are indicated by the variable $i$, and $j$ indicates the different filler types. The volume weighed VSSA for all dry materials except silica fume, VSSA matrix, is described in Section 3.2, see Eq. 2. Although, the material parameter study shows that both the $w / p$-ratio and $\phi$ are best described by the natural logarithm function, the prediction accuracy of the empirical equation was not improved by describing theses terms logarithmic in the equation.

One equation was developed for each of the four measured rheological parameters. The results show that the equation for the Bingham plastic viscosity, $\mu$, yields the highest prediction accuracy, with an $R^{2}=0.97$. The prediction accuracies for the mini slump flow, flow resistance ratio and yield stress are $R^{2}=0.94, R^{2}=0.91$ and $R^{2}=0.80$, respectively. As the original empirical equation in [18] predicts $\lambda_{q}$, it is chosen to present the new empirical equation for $\lambda_{q}$ for comparison in this paper, as well as the equation for the plastic viscosity, providing the highest accuracy. The $k_{x}$ and $n$ factors for the two empirical equations are presented, as well as the coefficient of determination, $R^{2}$ (Table 3). 
Table 3 - The $k_{x}$ and $n$ factors for the empirical equations for prediction of flow resistance ratio and plastic viscosity, as well as resulting $R^{2}$-values.

\begin{tabular}{|c|c|c|c|c|c|c|c|c|c|c|c|c|c|c|}
\hline & $n$ & $\overline{k_{1}}$ & $\boldsymbol{k}_{2}$ & $k_{3}$ & $k_{4}$ & & $k_{5}$ & & $k_{6}$ & $\boldsymbol{k}_{7}$ & $\boldsymbol{k}_{8}$ & $k_{9}$ & & $R^{2}$ \\
\hline$\lambda_{q}$ & 1 & 0.42 & 2.72 & 1.47 & \begin{tabular}{|l|} 
Std FA \\
Industry
\end{tabular} & $\begin{array}{l}0.06 \\
0.25\end{array}$ & $\begin{array}{l}\text { Std FA } \\
\text { Industry }\end{array}$ & $\begin{array}{l}0.31 \\
0.16\end{array}$ & 1.41 & 0.31 & 2.15 & $\begin{array}{l}\text { Fine } \\
\text { Int. } \\
\text { Coarse } \\
\text { VSI }\end{array}$ & $\begin{array}{l}0.47 \\
0.58 \\
0.47 \\
0.77\end{array}$ & 0.91 \\
\hline$\mu$ & 3 & 0.36 & 2.49 & 1.65 & \begin{tabular}{|l|} 
Std FA \\
Industry
\end{tabular} & $\begin{array}{l}0.18 \\
0.33\end{array}$ & $\begin{array}{l}\text { Std FA } \\
\text { Industry }\end{array}$ & $\begin{array}{l}0.56 \\
0.46\end{array}$ & 0.99 & 0.81 & 2.06 & $\begin{array}{l}\text { Fine } \\
\text { Int. } \\
\text { Coarse } \\
\text { VSI }\end{array}$ & $\begin{array}{l}0.72 \\
0.68 \\
0.63 \\
0.89\end{array}$ & 0.97 \\
\hline
\end{tabular}

The equations for the flow resistance ratio and the plastic viscosity are plotted (Figure 3 ). The figure shows that the prediction accuracy of the flow resistance ratio $\left(R^{2}=0.91\right)$ is much lower than observed in [18]. However, the coefficient of determination for the plastic viscosity $\left(R^{2}=\right.$ $0.97)$ is only slightly lower than for the three datasets predicted by the original empirical equation $\left(R^{2}=0.98-0.99\right)$.

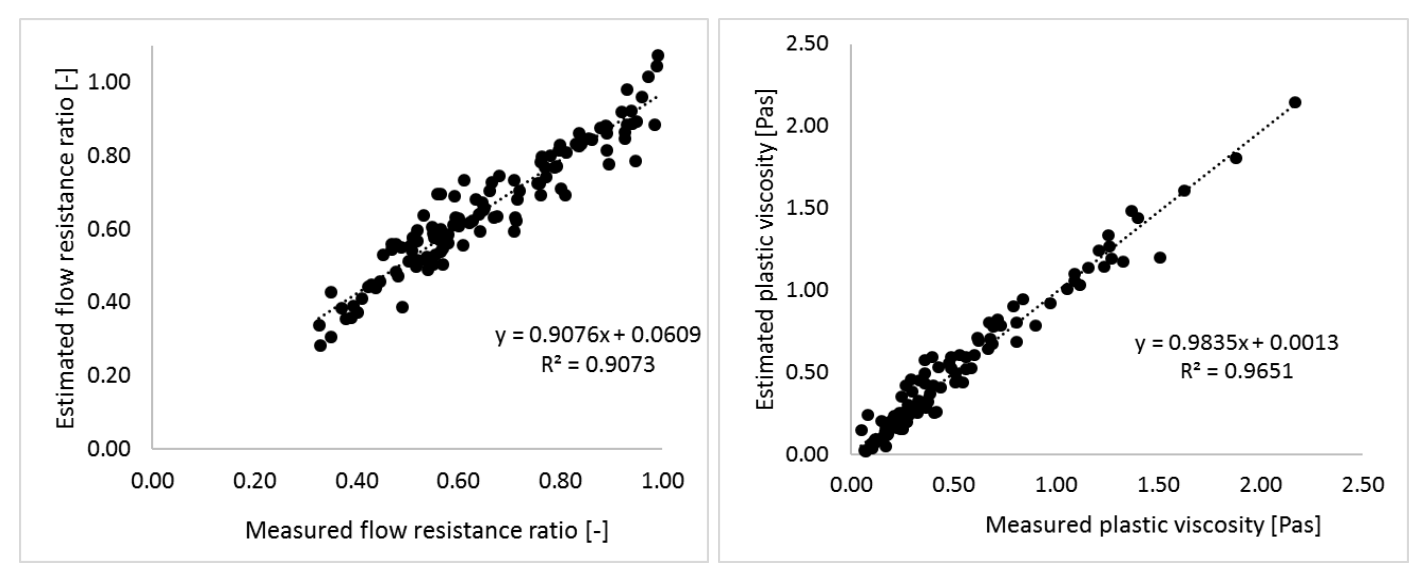

Figure 3-Measured and estimated values for the flow resistance ratio and the Bingham plastic viscosity.

It is found that the prediction accuracies for the equations may be further improved if the $k_{5}$ factor is a two-step function, changing at $w / c$-ratio $=0.50$. This adjustment of $k_{5}$ is considered reasonable to make, as the friction of the cement particles dominates more for low $w / c$-ratios, while at high $w / c$-ratio viscous flow dominates. In a study of cement grout injectability [29], it was found that fluidity of the grouts at $w / c$-ratio below 0.50 is decreasing in such a manner that injection operations could be hindered. It was also found that the rate of evolution of the apparent viscosity increased significantly for $w / c$-ratio below 0.50 . Hence, it seems reasonable that the $k_{5}$ factor changes at $w / c=0.5$. With this adjustment of $k_{5}$, the $R^{2}$ values increase to $R^{2}=0.98, R^{2}=0.95$ and $R^{2}=0.92$ for plastic viscosity, mini slump flow and flow resistance ratio, respectively. A similar two-step strategy was carried out for the $k_{4}$ factor, as the SP is known to reach saturation at a certain dosage level. However, the prediction accuracies were only improved by the third decimal via this change, hence $k_{4}$ were kept constant for each cement type. 
The new empirical model for prediction of flow resistance ratio shows lower prediction accuracy than the original empirical model. However, the FlowCyl test method and the resulting flow resistance ratio are not widely known, neither in Norway nor globally. Also, the cement pastes undergo high shear rates at the outlet of the FlowCyl, overshadowing the effect of the yield stress, making $\lambda_{q}$ dominated by the plastic viscosity $[30,31]$. Hence, it is considered beneficial that the new empirical equation provides the highest precision for the more known rheological parameters plastic viscosity and mini slump flow. The obtained $n$ and $k_{x}$ factors for the plastic viscosity are listed (Table 4) and the equation is plotted (Figure 4).

Table 4 - The $n$ and $k_{x}$ factors for the empirical equation predicting the plastic viscosity when $k_{5}$ differs for $w /$ c-ratio $\leq />0.50$.

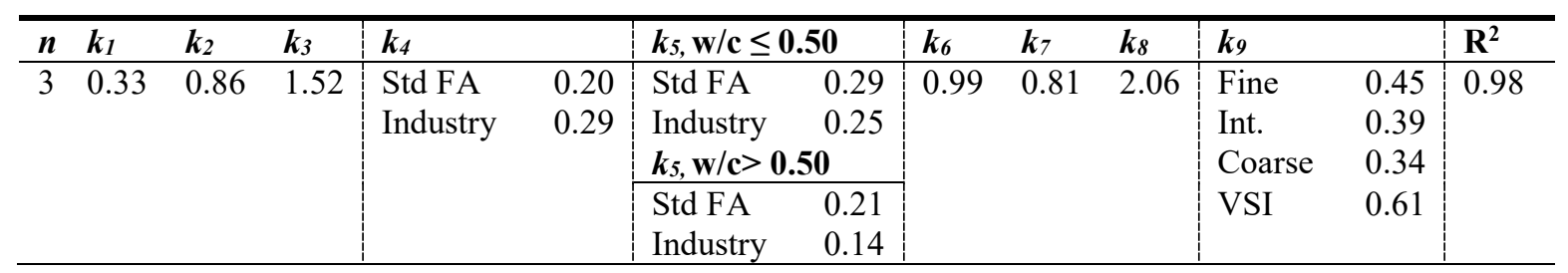

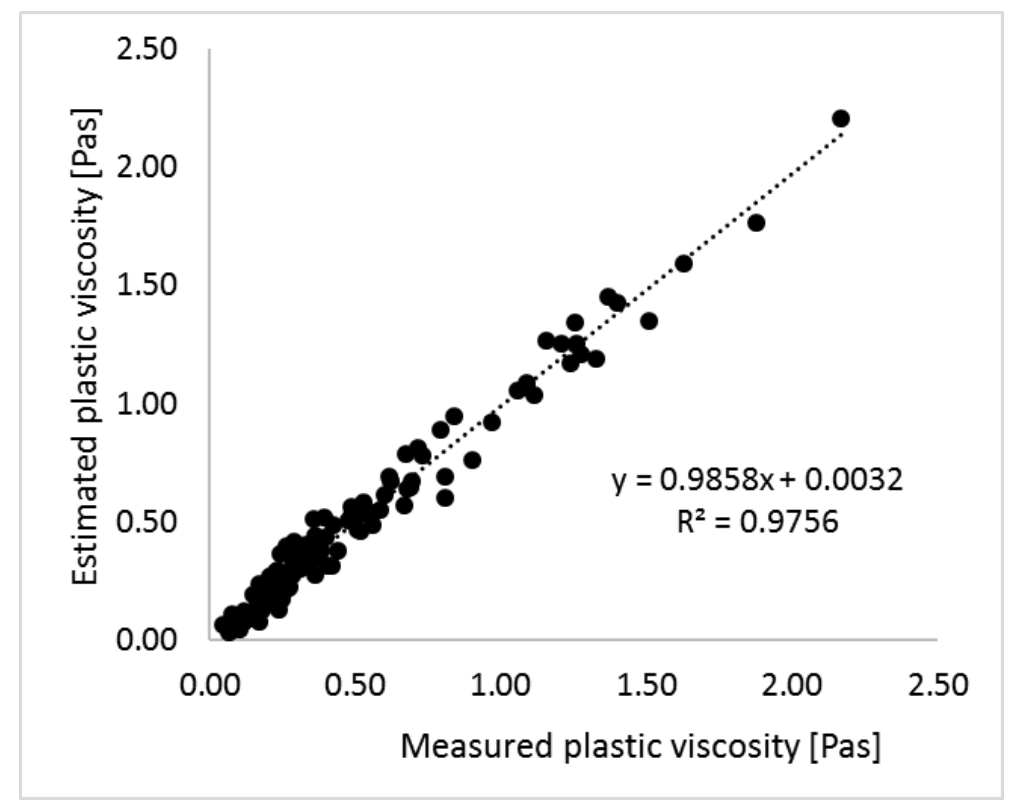

Figure 4 - Correlation between measured and predicted values from the new empirical equation for the plastic viscosity, where $k_{6}$ is a two-step function for $w / c$-ratio $\leq />0.50$.

The empirical equation for prediction of plastic viscosity provides an $R^{2}=0.98$ (Figure 4), which is approximately the same prediction accuracy as the equations presented in [18]. This is a surprisingly good result, considering that the equation is predicting a set of matrices that were tailor made to cover wide spectra of rheology, composition and powder materials. As pointed out in the introduction, the mix program consists of four different crushed fillers, two different cements, biotite, fly ash, silica fume and SP. Large variations occur in both SP dosages, $w / c$ and $f i / b$ ratios. This illustrates that the empirical equation developed in this work is capable of 
predicting a wide spectrum of matrices and is a promising proportioning tool for the concrete industry.

A limitation of the empirical equation is that the regression analysis needs to be performed for each set of new materials to obtain their $k_{x}$ factors. This means that for the equation to be optimized at a ready mix concrete plant, systematic testing of the given materials must be performed in advance. Also, further research should aim at simplifying the methodology of measuring the VSSA, in terms of comparing the Sedigraph measurements with other simpler and more industrial test methods, such as the Blaine test.

\section{5.}

\section{CONCLUSION}

In this paper, 117 matrices are presented, whereas 107 of these contain fillers from manufactured sand. The experimental testing of the matrices provides four rheological parameters: The flow resistance ratio, mini slump flow, Bingham yield stress and Bingham plastic viscosity. An empirical equation for rheology prediction is developed, and its applicability is investigated on the four measured rheological parameters. The results show that the equation provides good correlation to the plastic viscosity, with a coefficient of determination equal to $R^{2}=0.98$. Considering the large variety in mix design and materials in the mix program, the prediction accuracy is surprisingly good, and the empirical equation is evaluated to be a promising rheology prediction tool for the concrete industry.

\section{ACKNOWLEDGEMENT}

This paper is based on work performed within the MiKS project (Micro-proportioning with Crushed Sand), which is a Competence Project for the Industry funded by the Research Council of Norway (contract No. 247619) and industrial partners. The authors would like to thank the Research Council of Norway and the industrial partners Norcem AS, Skanska Norge AS and Feiring Bruk AS, for their financial support and for facilitating the interaction between research and industry. Special thanks go to former Ph.D. student in the project, Evgeny Ramenskiy, for performing rheological testing of 51 of the matrices, as well as researcher Malin Sletnes at SINTEF for performing testing of 11 matrices. The authors would also like to thank the master students Patricia Ysabel Sosa and Juni Christine Myhre Foslie for contributing to the testing of the remaining matrices.

\section{REFERENCES}

1. Ferraris C F, Obla K H \& Hill R: "The Influence of Mineral Admixtures on the Rheology of Cement Paste and Concrete". Cement and Concrete Research, Vol. 31, No. 2, 2001, pp. 245-255.

2. Krieger I M \& Dougherty T J: “A Mechanism for Non-Newtonian Flow in Suspensions of Rigid Spheres". Transactions of the society of rheology III, 1959, pp. 137-152.

3. Chong J S, Christiansen E B \& Baer A D: "Rheology of Concentrated Suspensions". Journal of applied polymer science, Vol. 15, 1971, pp. 2007-2021.

4. Mooney M: "The Viscosity of a Concentrated Suspension of Spherical Particles". Journal of Colloid Interface Science, Vol. 6, No. 2, 1951, pp. 162-170. 
5. Eilers H: "Die Viskosität von Emulsionen hochviskoser Stoffe als Funktion der Konzentration". ("The Viscosity of Emulsions of Highly Viscous Materials as a Function of Concentration"). Kolloid Zeitschrift, Vol. 97, No. 3, 1941, pp. 313-321 (in German).

6. Quemada D: "Rheology of Concentrated Disperse Systems and Minimum Energy Dissipation Principle”. Rheologica Acta, Vol. 16, 1977, pp. 82-94.

7. Robinson J V: "The Viscosity of Suspensions of Spheres". Journal of Physical Chemistry, Vol. 53, No. 7, 1949, pp. 1042-1056.

8. Spangenberg J, Scherer G W, Hopkins A B \& Torquato S: "Viscosity of Bimodal Suspensions with Hard Spherical Particles". Journal of Applied Physics, Vol. 116, No. 18, 2014.

9. Damineli B L, John V N, Lagerblad B \& Pileggi R G: "Viscosity Prediction of CementFiller Suspensions using Interference Model: A Route for Binder Efficiency Enhancement", Cement and Concrete Research, Vol. 84, 2016, pp. 8-19.

10. Buscall R, McGowan I J, Mills P D A, Stewart R F, Sutton D, White L R \& Yates G E: "The Rheology of Strongly-Flocculated Suspensions". Journal of Non-Newtonian Fluid Mechanics, Vol. 24, 1987, pp. 183-202.

11. Kapur P C, Scales P J, Boger D V \& Healy T W: "Yield Stress of Suspensions Loaded with Size Distributed Particles". AICHE Journal, Vol. 43, 1997, pp. 1171-1179.

12. Scales P J, Johnson S B, Healy T W \& Kapur P C: "Shear Yield Stress of Partially Flocculated Colloidal Suspensions". AICHE Journal, Vol. 44, 1998, pp. 538-544.

13. Zhou Z, Solomon M J, Scales P J \& Boger D V: "The Yield Stress of Concentrated Flocculated Suspensions of Size Distributed Particles". Journal of Rheology, Vol. 43, 1999, pp. 651-671.

14. Flatt R J \& Bowen P: "Yodel: A Yield Stress Model for Suspensions". Journal of the American Ceramic Society, Vol. 89, No. 4, 2006, pp.1244-1256.

15. Powers T C: "The Properties of Fresh Concrete". Wiley \& Sons, New York, USA, 1968, $664 \mathrm{pp}$.

16. Cepuritis R, Jacobsen S, Smeplass S, Mørtsell E, Wigum B J \& Ng S: "Influence of Crushed Aggregate Fines with Micro-Proportioned Particle Size Distributions on Rheology of Cement Paste". Cement and Concrete Composites, Vol. 80, 2017, pp. 64-79.

17. Skare E L, Cepuritis R, Spangenberg J, Ramenskiy E, Mørtsell E, Smeplass S, Jacobsen S: "Microproportioning Paste with Crushed Aggregate Filler by Use of Specific Surface Area", Proceedings, The $15^{\text {th }}$ International Congress on the Chemistry of Cement, Prague, Czech Republic, 2019. Ed. Gemrich J. ISSN 2523-935X, 10 pp.

18. Mørtsell E: "Modellering av Delmaterialenes Betydning for Betongens Konsistens". ("Modelling the Effect of Concrete Part Materials on Concrete Consistency"). (PhD Thesis). Norwegian University of Science and Technology, Department of Structural Engineering, Trondheim, Norway, 1996, 301 pp. (In Norwegian).

19. Cepuritis R: "Development of Crushed Sand for Concrete Production with Microproportioning". (PhD Thesis). Norwegian University of Science and Technology, Department of Structural Engineering, Trondheim, Norway, 2016, 386 pp.

20. Bengtsson $\mathrm{M}$ \& Evertsson CM: "Measuring characteristics of aggregate material from vertical shaft impact crushers". Minerals Engineering, Vol. 19 (15), 2006, pp. 1479-1486.

21. Wallevik O.H: "Den ferske betongens reologi og anvendelse på betong med og uten tilsetning av silikastøv». (Rheology of Fresh Concrete and Application to Concrete With and Without Addition of Silica Fume"). (PhD Thesis) Norges tekniske høgskole, Trondheim, Norway, 1990, 185 pp.

22. Sheiat S, Ranjbar N, Frellsen J, Skare E L, Cepuritis R, Jacobsen S \& Spangenberg J: "Neural Network Predictions of the Simulated Rheological Response of Cement Paste in the FlowCyl”. Neural Compututing \& Applications, Vol. 33, 2021, pp. 13027-13037. 
23. Great Wall Mineral, From the GWM Selection [Internet], $<$ http://greatwallmineral.com/index.asp? $I d=3>$ [Read 05.04.19]

24. Jacobsen S, Maage M, Smeplass S, Kjellsen K O, Sellevold E J, Lindgård J, Cepuritis R, Myrdal R, Bjøntegaard Ø, Geiker M et al.: "TKT 4215 Concrete Technology 1", Compendium, Norwegian University of Science and Technology, Department of Structural Engineering, Trondheim, Norway, 2016.

25. $\mathrm{Ng}$ S, Mujica H \& Smeplass S: "Design of a Simple and Cost-Efficient Mixer for Matrix Rheology Testing", Nordic Concrete Research, Vol. 51, No. 3, 2014, pp. 15-28.

26. Spangenberg J, da Silva W R L, Comminal R, Mollah M T, Andersen T J \& Stang H: "Numerical simulation of multi-layer 3D concrete printing", RILEM Technical Letters 6, 2021, pp. 119-123.

27. Comminal R, da Silva W R L, Andersen T J, Stang H \& Spangenberg J: "Modelling of 3D concrete printing based on computational fluid dynamics", Cement and Concrete Research, Vol. 138, 106256, 2020, 12 pages.

28. Comminal R, da Silva W R L, Andersen T J, Stang H \& Spangenberg J: "Influence of processing parameters on the layer geometry in 3D concrete printing: experiments and modelling", RILEM international Conference on Concrete and Digital Fabrication, 2020, pp.852-862.

29. Rosquoëta F, Alexis A, Khelidj A \& Phelipot A: "Experimental Study of Cement Grout: Rheological Behavior and Sedimentation". Cement and Concrete Research, Vol. 33, 2003, pp. 713-722.

30. Cepuritis R, Skare E L, Ramenskiy E, Mørtsell E, Smeplass S, Li S, Jacobsen S \& Spangenberg J: "Analysing Limitations of the FlowCyl as a One-Point Viscometer Test for Cement Paste". Construction and Building Materials, Vol. 218, 2019, pp. 333-340.

31. Skare E L, Jacobsen S, Cepuritis R, Smeplass S \& Spangenberg J: "Decreasing the Magnitude of Shear Rates in the FlowCyl". Proceedings, 5th fib Congress, Melbourne, Australia, 2018.

\section{APPENDIX A}

\section{Abbreviations used in the tables:}

$\mathbf{w} / \mathbf{b}=$ water-to-binder ratio by mass.

$\mathbf{S P}=$ superplasticiser dosage by mass of cement.-

$\mathbf{f i} / \mathbf{c}=$ filler-to-cement ratio by mass

$\mathbf{F A} / \mathbf{c}=$ fly ash-to-cement ratio by mass

$\mathbf{s} / \mathbf{c}=$ silica fume-to-cement ratio by mass

bio/fi $=$ biotite-to-filler ratio by mass

Table 5 - Outline of the different mix designs in Series 1 .

\begin{tabular}{lllllllll}
\hline No. & $\frac{w}{b}$ & $\frac{s p}{c}$ & $\frac{f i}{c}$ & $\frac{f a}{c}$ & $\frac{s}{c}$ & $\frac{b i o}{f i}$ & Cement & Filler \\
\hline 1 & 0.40 & 0.75 & 0.25 & - & - & - & Std FA & Coarse \\
2 & 0.40 & 0.75 & 0.32 & - & - & - & Std FA & Coarse
\end{tabular}


Nordic Concrete Research - Publ. No. NCR 65 - ISSUE 2 / 2021 - Article 1, pp. 1-18

\begin{tabular}{|c|c|c|c|c|c|c|c|c|}
\hline 3 & 0.40 & 0.75 & 0.39 & - & - & - & Std FA & Coarse \\
\hline 4 & 0.55 & 0.75 & 0.45 & - & - & - & Std FA & Coarse \\
\hline 5 & 0.55 & 0.75 & 0.52 & - & - & - & Std FA & Coarse \\
\hline 6 & 0.55 & 0.75 & 0.59 & - & - & - & Std FA & Coarse \\
\hline 7 & 0.70 & 0.75 & 0.60 & - & - & - & Std FA & Coarse \\
\hline 8 & 0.70 & 0.75 & 0.67 & - & - & - & Std FA & Coarse \\
\hline 9 & 0.70 & 0.75 & 0.72 & - & - & - & Std FA & Coarse \\
\hline 10 & 0.40 & 0.75 & 0.25 & - & - & - & Std FA & Intermediate \\
\hline 11 & 0.40 & 0.75 & 0.32 & - & - & - & Std FA & Intermediate \\
\hline 12 & 0.40 & 0.75 & 0.39 & - & - & - & Std FA & Intermediate \\
\hline 13 & 0.55 & 0.75 & 0.45 & - & - & - & Std FA & Intermediate \\
\hline 14 & 0.55 & 0.75 & 0.52 & - & - & - & Std FA & Intermediate \\
\hline 15 & 0.55 & 0.75 & 0.59 & - & - & - & Std FA & Intermediate \\
\hline 16 & 0.70 & 0.75 & 0.60 & - & - & - & Std FA & Intermediate \\
\hline 17 & 0.70 & 0.75 & 0.67 & - & - & - & Std FA & Intermediate \\
\hline 18 & 0.70 & 0.75 & 0.72 & - & - & - & Std FA & Intermediate \\
\hline 19 & 0.40 & 0.75 & 0.25 & - & - & - & Std FA & Fine \\
\hline 20 & 0.40 & 0.75 & 0.32 & - & - & - & Std FA & Fine \\
\hline 21 & 0.55 & 0.75 & 0.45 & - & - & - & Std FA & Fine \\
\hline 22 & 0.55 & 0.75 & 0.52 & - & - & - & Std FA & Fine \\
\hline 23 & 0.55 & 0.75 & 0.59 & - & - & - & Std FA & Fine \\
\hline 24 & 0.70 & 0.75 & 0.60 & - & - & - & Std FA & Fine \\
\hline 25 & 0.70 & 0.75 & 0.67 & - & - & - & Std FA & Fine \\
\hline 26 & 0.70 & 0.75 & 0.72 & - & - & - & Std FA & Fine \\
\hline 27 & 0.40 & 1.00 & 0.25 & - & - & - & Std FA & Intermediate \\
\hline 28 & 0.40 & 1.00 & 0.32 & - & - & - & Std FA & Intermediate \\
\hline 29 & 0.40 & 1.00 & 0.39 & - & - & - & Std FA & Intermediate \\
\hline 30 & 0.40 & 1.25 & 0.25 & - & - & - & Std FA & Intermediate \\
\hline 31 & 0.40 & 1.25 & 0.32 & - & - & - & Std FA & Intermediate \\
\hline 32 & 0.40 & 1.25 & 0.39 & - & - & - & Std FA & Intermediate \\
\hline 33 & 0.40 & 1.50 & 0.25 & - & - & - & Std FA & Intermediate \\
\hline 34 & 0.40 & 1.50 & 0.32 & - & - & - & Std FA & Intermediate \\
\hline
\end{tabular}


Nordic Concrete Research - Publ. No. NCR 65 - ISSUE 2 / 2021 - Article 1, pp. 1-18

$\begin{array}{lllllllll}35 & 0.40 & 1.50 & 0.39 & - & - & - & \text { Std FA } & \text { Intermediate } \\ 36 & 0.40 & 1.75 & 0.25 & - & - & - & \text { Std FA } & \text { Intermediate } \\ 37 & 0.40 & 1.75 & 0.32 & - & - & - & \text { Std FA } & \text { Intermediate } \\ 38 & 0.40 & 1.75 & 0.39 & - & - & - & \text { Std FA } & \text { Intermediate } \\ 39 & 0.55 & 1.00 & 0.45 & - & - & - & \text { Std FA } & \text { Intermediate } \\ 40 & 0.55 & 1.00 & 0.52 & - & - & - & \text { Std FA } & \text { Intermediate } \\ 41 & 0.55 & 1.00 & 0.59 & - & - & - & \text { Std FA } & \text { Intermediate } \\ 42 & 0.55 & 1.25 & 0.45 & - & - & - & \text { Std FA } & \text { Intermediate } \\ 43 & 0.55 & 1.25 & 0.52 & - & - & - & \text { Std FA } & \text { Intermediate } \\ 44 & 0.55 & 1.25 & 0.59 & - & - & - & \text { Std FA } & \text { Intermediate } \\ 45 & 0.55 & 1.50 & 0.45 & - & - & - & \text { Std FA } & \text { Intermediate } \\ 46 & 0.55 & 1.50 & 0.52 & - & - & - & \text { Std FA } & \text { Intermediate } \\ 47 & 0.55 & 1.50 & 0.59 & - & - & - & \text { Std FA } & \text { Intermediate } \\ 48 & 0.55 & 1.75 & 0.45 & - & - & - & \text { Std FA } & \text { Intermediate } \\ 49 & 0.55 & 1.75 & 0.52 & - & - & - & \text { Std FA } & \text { Intermediate } \\ 50 & 0.55 & 1.75 & 0.59 & - & - & - & \text { Std FA } & \text { Intermediate } \\ 51 & 0.40 & 0.75 & 0.32 & - & - & 0.01 & \text { Std FA } & \text { Int. + mica } \\ 52 & 0.40 & 0.75 & 0.32 & - & - & 0.02 & \text { Std FA } & \text { Int. + mica } \\ 53 & 0.40 & 0.75 & 0.32 & - & - & 0.03 & \text { Std FA } & \text { Int. + mica } \\ 54 & 0.40 & 0.75 & 0.32 & - & - & 0.05 & \text { Std FA } & \text { Int. + mica } \\ 55 & 0.40 & 0.75 & 0.32 & - & - & 0.10 & \text { Std FA } & \text { Int. + mica }\end{array}$

Table 6-Outline of the different mix designs in Series $1 b$.

\begin{tabular}{lcccccll}
\hline No. & $\frac{w}{b}$ & $\frac{s p}{c}$ & $\frac{f i}{c}$ & $\frac{f a}{c}$ & $\frac{s}{c}$ & Cement & Filler \\
\hline 1 & 0.55 & 0.75 & 0.53 & 0.00 & 0.04 & Std FA & Intermediate \\
2 & 0.55 & 0.75 & 0.61 & 0.00 & 0.04 & Std FA & Intermediate \\
3 & 0.55 & 0.75 & 0.55 & 0.00 & 0.09 & Std FA & Intermediate \\
4 & 0.55 & 0.75 & 0.64 & 0.00 & 0.09 & Std FA & Intermediate \\
5 & 0.55 & 0.75 & 0.53 & 0.00 & 0.04 & Std FA & VSI \\
6 & 0.55 & 0.75 & 0.61 & 0.00 & 0.04 & Std FA & VSI \\
7 & 0.55 & 0.75 & 0.78 & 0.26 & 0.05 & Std FA & VSI
\end{tabular}


Nordic Concrete Research - Publ. No. NCR 65 - ISSUE 2 / 2021 - Article 1, pp. 1-18

$\begin{array}{llllllll}8 & 0.55 & 0.75 & 0.67 & 0.26 & 0.05 & \text { Std FA } & \text { Intermediate } \\ 9 & 0.55 & 0.75 & 0.78 & 0.26 & 0.05 & \text { Std FA } & \text { Intermediate } \\ 10 & 0.55 & 0.75 & 0.89 & 0.61 & 0.14 & \text { Std FA } & \text { Intermediate } \\ 11 & 0.55 & 0.75 & 1.04 & 0.61 & 0.14 & \text { Std FA } & \text { Intermediate } \\ 12 & 0.55 & 0.75 & 0.71 & 0.28 & 0.11 & \text { Std FA } & \text { Intermediate } \\ 13 & 0.55 & 0.75 & 0.89 & 0.61 & 0.14 & \text { Std FA } & \text { Intermediate } \\ 14 & 0.55 & 0.75 & 1.04 & 0.61 & 0.14 & \text { Std FA } & \text { Intermediate }\end{array}$

Table 7 -Outline of the different mix designs in Series $2 a$.

\begin{tabular}{lrrrrrll}
\hline No. & $\frac{w}{b}$ & $\frac{S p}{c}$ & $\frac{f i}{c}$ & $\frac{f a}{c}$ & $\frac{S}{c}$ & Cement & Filler \\
\hline 1 & 0.40 & 0.75 & 0.28 & 0.00 & - & Industry & Intermediate \\
2 & 0.40 & 1.50 & 0.28 & 0.00 & - & Industry & Intermediate \\
3 & 0.55 & 0.75 & 0.51 & 0.00 & - & Industry & Intermediate \\
4 & 0.55 & 0.75 & 0.59 & 0.00 & - & Industry & Intermediate \\
5 & 0.55 & 1.50 & 0.51 & 0.00 & - & Industry & Intermediate \\
6 & 0.55 & 1.50 & 0.59 & 0.00 & - & Industry & Intermediate \\
7 & 0.40 & 1.50 & 0.36 & 0.00 & - & Industry & Intermediate \\
8 & 0.60 & 0.60 & 0.17 & 0.00 & - & Industry & Fine \\
9 & 0.73 & 0.60 & 0.39 & 0.00 & - & Industry & Fine \\
10 & 0.55 & 0.75 & 0.51 & 0.00 & - & Industry & VSI \\
11 & 0.55 & 0.75 & 0.59 & 0.00 & - & Industry & VSI \\
12 & 0.50 & 0.60 & 0.25 & 0.25 & - & Industry & Fine \\
13 & 0.50 & 0.60 & 0.31 & 0.54 & - & Industry & Fine \\
14 & 0.65 & 0.60 & 0.25 & 0.25 & - & Industry & Fine \\
15 & 0.81 & 0.60 & 0.56 & 0.11 & - & Industry & Fine \\
16 & 0.76 & 0.60 & 0.48 & 0.23 & - & Industry & Fine \\
17 & 0.80 & 0.60 & 0.64 & 0.56 & - & Industry & Fine \\
18 & 0.44 & 1.50 & 0.35 & 0.25 & - & Industry & Intermediate
\end{tabular}

Table 8 -Outline of the different mix designs in Series $2 b$. 
Nordic Concrete Research - Publ. No. NCR 65 - ISSUE 2 / 2021 - Article 1, pp. 1-18

\begin{tabular}{|c|c|c|c|c|c|c|c|}
\hline No. & $\frac{w}{b}$ & $\frac{s p}{c}$ & $\frac{f i}{c}$ & $\frac{f a}{c}$ & $\frac{S}{\bar{c}}$ & Cement & Filler \\
\hline 1 & 0.55 & 0.75 & 0.53 & 0.00 & 0.04 & Industry & Intermediate \\
\hline 2 & 0.55 & 0.75 & 0.61 & 0.00 & 0.04 & Industry & Intermediate \\
\hline 3 & 0.55 & 0.75 & 0.55 & 0.00 & 0.09 & Industry & Intermediate \\
\hline 4 & 0.55 & 0.75 & 0.64 & 0.00 & 0.09 & Industry & Intermediate \\
\hline 5 & 0.51 & 0.75 & 0.55 & 0.00 & 0.09 & Industry & Intermediate \\
\hline 6 & 0.51 & 0.75 & 0.61 & 0.00 & 0.04 & Industry & Intermediate \\
\hline 7 & 0.51 & 1.00 & 0.64 & 0.00 & 0.09 & Industry & Intermediate \\
\hline 8 & 0.51 & 1.25 & 0.64 & 0.00 & 0.09 & Industry & Intermediate \\
\hline 9 & 0.51 & 1.50 & 0.64 & 0.00 & 0.09 & Industry & Intermediate \\
\hline 10 & 0.55 & 0.75 & 0.67 & 0.26 & 0.05 & Industry & Intermediate \\
\hline 11 & 0.55 & 0.75 & 0.78 & 0.26 & 0.05 & Industry & Intermediate \\
\hline 12 & 0.55 & 0.75 & 0.89 & 0.61 & 0.14 & Industry & Intermediate \\
\hline 13 & 0.55 & 0.75 & 1.04 & 0.61 & 0.14 & Industry & Intermediate \\
\hline 14 & 0.55 & 0.75 & 0.71 & 0.28 & 0.11 & Industry & Intermediate \\
\hline 15 & 0.55 & 0.75 & 0.89 & 0.61 & 0.14 & Industry & Intermediate \\
\hline 16 & 0.55 & 0.75 & 1.04 & 0.61 & 0.14 & Industry & Intermediate \\
\hline 17 & 0.42 & 1.00 & 0.37 & 0.26 & 0.05 & Industry & Intermediate \\
\hline 18 & 0.42 & 1.25 & 0.37 & 0.26 & 0.05 & Industry & Intermediate \\
\hline 19 & 0.42 & 1.50 & 0.37 & 0.26 & 0.05 & Industry & Intermediate \\
\hline 20 & 0.55 & 0.75 & 0.78 & 0.26 & 0.05 & Industry & VSI \\
\hline
\end{tabular}

Table 9 - Outline of the different mix designs in Series $2 c$.

\begin{tabular}{lccccccl}
\hline No. & $\frac{w}{b}$ & $\frac{s p}{c}$ & $\frac{f i}{c}$ & $\frac{f a}{c}$ & $\frac{s}{c}$ & Cement & Filler \\
\hline 1 & 0.50 & 0.60 & 0.00 & 0.00 & - & Industry & Fine \\
2 & 0.45 & 0.60 & 0.00 & 0.00 & - & Industry & Fine \\
3 & 0.50 & 0.60 & 0.00 & 0.25 & - & Industry & Fine \\
4 & 0.50 & 0.60 & 0.00 & 0.43 & - & Industry & Fine \\
5 & 0.50 & 0.60 & 0.00 & 0.54 & - & Industry & Fine
\end{tabular}


Nordic Concrete Research - Publ. No. NCR 65 - ISSUE 2 / 2021 - Article 1, pp. 1-18

$\begin{array}{llllllll}6 & 0.45 & 0.60 & 0.00 & 0.54 & - & \text { Industry } & \text { Fine } \\ 7 & 0.50 & 0.60 & 0.00 & 0.00 & - & \text { Industry } & \text { Fine } \\ 8 & 0.53 & 0.60 & 0.00 & 0.23 & - & \text { Industry } & \text { Fine } \\ 9 & 0.55 & 0.60 & 0.00 & 0.47 & - & \text { Industry } & \text { Fine } \\ 10 & 0.57 & 0.60 & 0.00 & 0.82 & - & \text { Industry } & \text { Fine }\end{array}$

